\title{
Knowledge, Attitude and Practice of Community Pharmacists on Medication Safety during Pregnancy: A Cross-sectional Study
}

\author{
Goruntla Narayana1,*, Payal Pandey², Alluri Gullakunta Ashok Kumar², Anil Kumar², Bhupalam Pradeepkumar', Kasturi Vishwanathasetty \\ Veerabhadrappa ${ }^{3}$ \\ 'Department of Pharmacy Practice, Raghavendra Institute of Pharmaceutical Education and Research (RIPER), Anantapur, Andhra Pradesh, INDIA. \\ ${ }^{2}$ Raghavendra Institute of Pharmaceutical Education and Research (RIPER), Anantapur, Andhra Pradesh, INDIA.

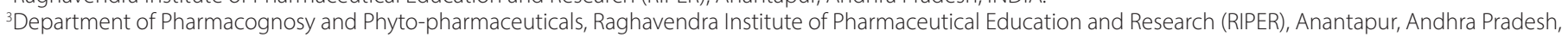 \\ INDIA.
}

\begin{abstract}
Background: Safe medication use during pregnancy requires a great understanding of the benefits and risks associated upon use of the drug. Community Pharmacists (CPs) are the most accessible health care professionals for the pregnant women to get safety information about drugs. Evaluation of Knowledge, Attitude and Practices (KAP) of community pharmacists on medication safety during pregnancy. Methods: A crosssectional study was conducted among community pharmacists of various community pharmacies located in Anantapur district. A total of $403 \mathrm{CPs}$ were enrolled and subjected for interview by using pre-validated selfadministered KAP questionnaire on medication safety during pregnancy. Descriptive statistics were used to represent the socio-demographic characteristics and KAP levels. Chi-square test was used to associate demographic profile with KAP levels. Results: A total of 403 community Pharmacists (CPs) were enrolled in the study. Majority of the pharmacists are males $(345 ; 85.6 \%)$, residing in semi-urban area $(184 ; 45.6 \%)$, possess diploma in pharmacy $(232 ; 57.5 \%)$ and having more than 10 years' of experience. Among $403 \mathrm{CPs}$, only $21(5.2 \%)$ had good knowledge, 380 (94.2\%) had positive attitude and 119 (29.5\%) have safe practice towards
\end{abstract}

medication safety during pregnancy. Respondent's age, qualification and experience were significantly associated with good knowledge and safe practices. Conclusion: Community pharmacists are having a positive attitude and some knowledge about safe medication use in pregnant women. Still, there is a wide gap in knowledge levels and practices of CPs towards safe medication use in pregnant women. This gap can be fulfilled by providing focused educational intervention to all CPs.

Key words: Knowledge, Attitude, Practice, Community Pharmacist, Medication Safety, Pregnancy, South India.

\section{Correspondence}

Prof. Goruntla Narayana,

Head and Associate Professor, Department of Pharmacy Practice, Raghavendra Institute of Pharmaceutical Education and Research (RIPER), K.R. Palli Cross, Anantapur-515721, Andhra Pradesh, INDIA.

Phone no: +919959835600

Email: narayanagoruntla@gmail.com

DOI: $10.5330 /$ ijpi.2019.4.40

\section{INTRODUCTION}

According to World Health Organization (WHO), pregnancy is defined as "woman carries an embryo and fetus in her womb for a period of nine months". For most women this is a time of great happiness and fulfillment. ${ }^{1}$ However, during pregnancy, both the woman and her developing child face various health risks, so all pregnancies will be closely monitored by skilled health care professionals. ${ }^{2}$ The number of women taking medications during pregnancy has been drastically raised from past 3-4 decades. It was estimated that $90 \%$ of pregnant women take at least one prescription or non-prescription drug other than a vitamin or mineral supplements. ${ }^{3}$ This raise in medication consumption during pregnancy is majorly due to, change in demographic characteristics, high prevalence of pre-existing co-morbidities and obstetric conditions. ${ }^{4,5}$ The most common chronic disorders warrant drug therapy in pregnancy include renal disease, diabetes, depression, thyroid disorders, cardiovascular disorders and asthma. If appropriate drug therapy is not provided in these conditions, it may lead to develop adverse effects on the fetus and require post-natal care of the newborn. ${ }^{6}$

Most of the drugs do not comprise clinical trial evidence on pregnancy risk, this makes health care professionals to enrich their knowledge about drug acts as a teratogen before prescribing or dispensing of drugs in the pregnant women. ${ }^{7}$ Medication use during pregnancy cannot be completely avoided, however, change in pharmacokinetics and placental crossing of many drugs may attribute to cause significant harm in the growing fetus. ${ }^{8}$ Safe medication use during pregnancy requires a great understanding of the benefits and risks associated with pregnant women and fetuses upon use of the drug.

Globally, pharmacists are considered as medication experts with great knowledge in pharmacology, pharmacokinetics and trained to apply evidence in clinical practice. The pharmacist must in a position to counsel pregnant women about the risks associated with prescription and nonprescription drugs, traditional medicines and abuse of substances such as alcohol and nicotine like substances. ${ }^{9}$ Community pharmacists are the most accessible personal to the general public in all health care professionals. They have a huge responsibility in safe medication delivery in pregnant women by dispensing safest drugs and providing appropriate information during pregnancy to reduce the possibility and potential risks of the drugs. ${ }^{10}$ In India, provision of quality community pharmacy services is severely compromised by huge population burden, growing unemployed youth and easy availability of manpower with a low cost and high number of non-qualified pharmacists owing the pharmacy. ${ }^{11}$ There was a lack evidence in relation to assessment of community pharmacist's knowledge, attitude and practice towards medication safety during pregnancy in Indian settings. The objective of this study was to evaluate the community pharmacist's knowledge, attitude and practice towards medication safety during pregnancy. 


\section{MATERIALS AND METHODS}

\section{Study design and participants}

A cross-sectional study was conducted in community pharmacy premises, which are located in and around the Anantapur district, Andhra Pradesh, India. All retail community pharmacies which serves medication needs of the residing public by a qualified pharmacist are eligible sites for this study. The study was conducted over a period of six months from December 2017 to June 2018. A due permission was sought from all community pharmacy owners before initiation of the study. The study was approved by RIPER institutional Review Board with a registration number of (RIPER/IRB/PP/2017/010). Working community pharmacists who are qualified and having a minimum of one year experience were included in the study. Community pharmacists who are not willing to participate were excluded from the study.

\section{Sample size determination}

The required sample size was calculated as 384 by using Epi Info 7 Dos version 3.5.1 software (Centers for Disease Control and Prevention, Clifton Road, Atlanta, USA) with an assumption of $50 \%$ of community pharmacists have optimal knowledge toward medication safety during pregnancy, $95 \%$ confidence interval and $5 \%$ precision. With a $5 \%$ of nonresponse rate the final sample size was calculated as 403 .

\section{Sampling technique}

A total of 1900 community pharmacists are working in both retail (1498) and whole sale (402) pharmacies settings of Anantapur district. All retail pharmacy addresses are gathered from Drug Regulatory Office located in Anantapur City. All 1498 retail pharmacies were assigned a number and a simple random sampling technique (random number generator) was used to select the 403 study samples.

\section{Study tool}

A total of 403 randomly selected community pharmacists from various community pharmacy premises located in various areas (rural and urban) of Anantapur district were enrolled and subjected for a face to face interview by using pre-validated questionnaire about medication safety during pregnancy. The questionnaire comprises of two parts to gather information related to socio-demographic characteristics and KAP towards medication safety during pregnancy among community pharmacists. The socio-demographic characteristics included are age, gender, type of working pharmacy, location of working pharmacy, qualification and number of prescriptions dispensed per day.

\section{Knowledge toward medication safety during pregnancy}

The community pharmacist's knowledge regarding medication safety during pregnancy was assessed by using a 32 point scale. The maximum points expected were 32 and a minimum of zero. Points to, aware of teratogen definition ( 1 point), knowledge about FDA pregnancy drug risk categories (each category 1 point; total $=5$ points), knowledge about 10 prescription drugs safety in pregnant women (each drug 1 point: total $=10$ points), knowledge about 8 non-prescription drugs safety in pregnant women (each drug 1 point: total $=8$ points), knowledge about 5 herbal drugs safety in pregnant women (each drug 1 point: total=5 points) and knowledge about physical activity, nutritional interventions ( 3 points). If the responding pharmacist scores $\geq 16$ points considered as having optimal knowledge and less $<16$ points considered as having poor knowledge about medication safety during pregnancy.

\section{Attitude toward medication safety during pregnancy}

The community pharmacist's attitude was assessed by putting eight statements regarding medication safety during pregnancy on Likert's scale. Each statement on Likens scale has both positive and negative replies that ranged from strongly agree 5 , agree 4 , neither agree or nor disagree 3 , disagree 2 and strongly disagree 1 . The maximum score expected from all statements are 40 and minimum of 8 . If the persons scored above or equal to 20 , will be considered as a positive attitude and $<20$ considered as a negative attitude toward medication safety during pregnancy.

\section{Practice toward medication safety during pregnancy}

Community pharmacists dispensing practice toward medication safety during pregnancy was assessed by using five closed ended questions. If the respondent says "yes" to less than four question will be considered having irregular practice towards medication safety during pregnancy. If the respondent says "yes" to four or more questions will be considered having regular practice towards medication safety during pregnancy.

\section{Data analysis}

Descriptive statistics like mean, proportion, standard deviation and frequency were used to represent the socio-demographic characteristics and KAP levels of the respondents. Chi-square test was used to associate socio-demographic profile with KAP levels of medication safety during pregnancy. $P$ value less than 0.05 was considered as statistically significant.

\section{RESULTS}

A total of 403 community pharmacists were enrolled in the study. Most of the respondents $(206 ; 51.1 \%)$ are between the age 31 and 40 years, with a mean age of $34.1 \pm 7.59$. The majority of the pharmacists is males $(345 ; 85.6 \%)$, semi-urban area $(184 ; 45.6 \%)$, diploma in pharmacy qualification $(232 ; 57.5 \%)$, more than 10 years' experience and dispenses 301 to 500 prescriptions per day as shown in Table 1 .

Most of the community pharmacists are aware about teratogens (342; $84.8 \%)$. Very less number of pharmacists are having knowledge regarding all pregnancy risk categories $(22 ; 5.4 \%)$, answered about safe use of ten prescription drugs $(58 ; 14.4 \%)$, eight non-prescription drugs (45; $11.1 \%)$ and five herbal drugs $(36 ; 8.9 \%)$ in pregnancy. More than $70 \%$ of pharmacists are aware about nutritional and physical activity requirement in pregnant women as depicted in Table 2.

Among all community pharmacists, most of the pharmacist's attitude was "strongly agree" and "agree" about various statements about safe medication use during pregnancy as represented in Table 3. The majority of the community pharmacists are shown unsafe dispensing practice for pregnant women as shown in Table 4.

Among all respondents, majority of the respondents have poor knowledge $(218 ; 54.1 \%)$, positive attitude $(380 ; 94.2 \%)$ and unsafe dispensing practice $(284 ; 70.5 \%)$ of medication used in pregnant women as shown in Table 5. An association of respondent's socio-demographic characteristics towards KAP of medication safety during pregnancy was shown in Table 6.

\section{DISCUSSION}

KAP studies in community pharmacists concerning about safe medication use during pregnancy are very limited. Community pharmacist plays a vital role in promotion of medication safety during pregnancy by providing appropriate medication counseling and drug information to pregnant women. ${ }^{12}$ This study explores the knowledge gap and current practices and future requirements of community pharmacists in relation to medication safety during pregnancy. The USFDA classified all drugs into five categories (A, B, C, D and X) to promote safe use and to prevent teratogenic effects of drugs in pregnant women and fetus. Pharmacist need to aware about the drugs comes under D and X category, because these drugs are proven teratogens in pregnant women. The study findings revealed that $80.6 \%$ of the pharmacists are unaware about USFDA pregnancy risk categories and only $5.4 \%$ of them were able to answer all 
Table 1: Demographic characteristics of community $(n=403)$.

\begin{tabular}{|c|c|}
\hline Characteristics & Frequency (\%) \\
\hline \multicolumn{2}{|l|}{ Age: } \\
\hline$\leq 20$ Years & $13(3.2)$ \\
\hline $21-30$ years & $99(24.5)$ \\
\hline $31-40$ years & $206(51.1)$ \\
\hline $41-50$ years & $75(18.6)$ \\
\hline$>50$ Years & $10(2.5)$ \\
\hline Mean \pm SD & $34.1 \pm 7.59$ \\
\hline \multicolumn{2}{|l|}{ Gender } \\
\hline Male & $345(85.6)$ \\
\hline Female & $58(14.3)$ \\
\hline \multicolumn{2}{|c|}{ Location of Community Pharmacy: } \\
\hline Rural & $280(69.4)$ \\
\hline Urban & $123(30.5)$ \\
\hline \multicolumn{2}{|l|}{ Qualification: } \\
\hline Diploma in Pharmacy & $232(57.5)$ \\
\hline Bachelor in Pharmacy & $96(23.8)$ \\
\hline Master in Pharmacy & $75(18.6)$ \\
\hline \multicolumn{2}{|l|}{ Experience: } \\
\hline Less than 5 years & $33(8.2)$ \\
\hline From 5 to 9 years & $49(12.1)$ \\
\hline From 10 to 14 years & $85(21.0)$ \\
\hline From 15 to 19 years & $93(23.1)$ \\
\hline From 20 to 24 years & $75(18.6)$ \\
\hline$\geq 25$ years & $68(16.8)$ \\
\hline \multicolumn{2}{|c|}{ Average number of prescriptions dispensed per day: } \\
\hline$\leq 100$ & $25(6.2)$ \\
\hline $101-200$ & $59(14.6)$ \\
\hline $201-300$ & $71(17.6)$ \\
\hline $301-400$ & $106(26.3)$ \\
\hline $401-500$ & $120(29.8)$ \\
\hline$>500$ & $22(5.4)$ \\
\hline
\end{tabular}

SD: Standard Deviation

risk categories. Similar type of findings are also observed in the study conducted by Kamuhabwa A et al. ${ }^{13}$

The study found that, most of the community pharmacists were answered prescription drugs like Valproicacid (192; 47.6\%), Isotretinoin (124; 30.7\%), Phenobarbitone (108; 26.8\%), non-prescription drugs like Aspirin (164; 40.7\%), Dextromethorphan $(158 ; 39.2 \%)$ and herbal medicines like Senna (222; 55.1\%), Ipecac (156; 38.7\%) are not safe during first trimester of pregnancy. Similar type of findings are also observed in the study conducted by Morgan et al. ${ }^{14}$ Most of the community pharmacists are having poor knowledge 344 (85.3\%) and unsafe practice 284 (70.5\%) towards medication use during pregnancy. Similar type of findings are also observed in the study conducted by Damase-Michel C et al. ${ }^{15}$ These findings suggest that, community pharmacist needs to undergo continuous training and educational program about medication safety during pregnancy. This will promote safe medication practice during pregnancy and prevents unwanted effects offered by the drugs.

Community Pharmacists (CPs) are the most accessible health care personnel to the public. Community pharmacist plays a major in providing information about OTC drugs, herbal medicines and dietary products. ${ }^{16}$ The study found that most of the CPs are aware about dietary products (289; 71.7\%) need to be taken during pregnancy, but a very less number
Table 2: Knowledge of community pharmacists towards medication safety during pregnancy.

\begin{tabular}{|c|c|}
\hline Variable & Frequency (\%) \\
\hline Aware about teratogens & $342(84.8)$ \\
\hline $\begin{array}{c}\text { Knowledge about FDA drug risk category in pregnant } \\
\text { women }\end{array}$ & $22(5.4)$ \\
\hline Category A & $78(19.3)$ \\
\hline Category B & $57(14.1)$ \\
\hline Category C & $22(5.4)$ \\
\hline Category D & $34(8.4)$ \\
\hline Category X & $35(8.7)$ \\
\hline Don’t know & $325(80.6)$ \\
\hline $\begin{array}{l}\text { Knowledge about safe use of prescription drugs in } \\
\text { pregnancy }\end{array}$ & $58(14.4)$ \\
\hline Valproicacid & $192(47.6)$ \\
\hline Tetracycline & $239(59.3)$ \\
\hline Statins & $84(20.8)$ \\
\hline Phenobarbitone & $108(26.8)$ \\
\hline OCP & $92(22.8)$ \\
\hline Lamotrigine & $58(14.4)$ \\
\hline Ciprofloxacin & $234(58.1)$ \\
\hline Isotretinoin & $124(30.7)$ \\
\hline Budesonide inhaler & $94(23.3)$ \\
\hline Amoxicillin & $202(50.1)$ \\
\hline Don’t know & $169(41.9)$ \\
\hline $\begin{array}{l}\text { Knowledge about safe use of non-prescription drugs in } \\
\text { pregnancy }\end{array}$ & $45(11.1)$ \\
\hline Ibuprofen & $87(21.6)$ \\
\hline Pseudoephedrine Hydrochloride & $45(11.1)$ \\
\hline Guaifenesin & $58(14.4)$ \\
\hline Dextromethorphan hydro bromide & $158(39.2)$ \\
\hline Bismuth subsalicylate & $92(22.8)$ \\
\hline Acetaminophen & $234(58.1)$ \\
\hline Aspirin & $164(40.7)$ \\
\hline Supplement Vitamin A & $182(45.1)$ \\
\hline Don’t know & $169(41.9)$ \\
\hline $\begin{array}{l}\text { Knowledge about safe use of herbal medicine during } \\
\text { pregnancy }\end{array}$ & $36(8.9)$ \\
\hline Senna & $222(55.1)$ \\
\hline Ginseng & $124(30.7)$ \\
\hline Ipecac & $156(38.7)$ \\
\hline Shanchpushpi & $98(24.3)$ \\
\hline Ephedra & $36(8.9)$ \\
\hline Don’t know & $181(44.9)$ \\
\hline $\begin{array}{l}\text { Knowledge about nutritional and physical activity } \\
\text { intervention during pregnancy }\end{array}$ & $289(71.7)$ \\
\hline Physical activity & $312(77.4)$ \\
\hline Daily oral iron and folic acid supplementation & $350(86.8)$ \\
\hline Daily calcium supplementation & $289(71.7)$ \\
\hline Don’t know & $114(28.2)$ \\
\hline
\end{tabular}

FDA: Food and Drug Administration; OCP: Oral Contraceptive Pill 
Table 3: Attitude of community pharmacists on medication safety during pregnancy.

\begin{tabular}{|c|c|c|c|c|c|}
\hline \multirow[t]{2}{*}{ Variable } & \multicolumn{5}{|c|}{ Frequency (\%) } \\
\hline & $\begin{array}{l}\text { Strongly } \\
\text { agree }\end{array}$ & Agree & $\begin{array}{c}\text { Neither agree nor } \\
\text { disagree }\end{array}$ & Disagree & $\begin{array}{l}\text { Strongly } \\
\text { disagree }\end{array}$ \\
\hline $\begin{array}{l}\text { You are more confident about } \\
\text { dispensing drugs during pregnancy }\end{array}$ & $204(50.6)$ & $90(22.3)$ & $43(10.6)$ & $47(11.6)$ & $19(4.7)$ \\
\hline $\begin{array}{l}\text { An extra caution is required while } \\
\text { dispensing drugs during pregnancy }\end{array}$ & $181(44.9)$ & $122(30.2)$ & $50(12.4)$ & $33(8.1)$ & $17(4.2)$ \\
\hline $\begin{array}{l}\text { All OTC drugs are not safe in } \\
\text { pregnant women }\end{array}$ & $60(14.8)$ & $222(55.0)$ & $44(10.9)$ & $49(12.15)$ & $28(6.9)$ \\
\hline Only some drugs are proven teratogen & $181(44.9)$ & $63(15.6)$ & $59(14.6)$ & $55(13.6)$ & $45(11.1)$ \\
\hline $\begin{array}{l}\text { Only some of the antibiotics are } \\
\text { contra indicated in pregnant women }\end{array}$ & $198(49.1)$ & $80(19.8)$ & $54(13.3)$ & $37(9.1)$ & $34(8.4)$ \\
\hline $\begin{array}{l}\text { Diuretics and Beta blockers are contra } \\
\text { indicated in pregnant women for the } \\
\text { management of hypertension }\end{array}$ & $163(40.4)$ & $91(22.5)$ & $55(13.6)$ & $52(12.9)$ & $42(10.4)$ \\
\hline $\begin{array}{l}\text { Most of the presently available drugs } \\
\text { are safe during pregnancy }\end{array}$ & $144(35.7)$ & $123(30.5)$ & $76(18.8)$ & $39(9.6)$ & $21(5.2)$ \\
\hline $\begin{array}{l}\text { I take a chance and dispense safest } \\
\text { drugs in pregnant women }\end{array}$ & $183(45.4)$ & $50(12.4)$ & $95(23.5)$ & $44(10.9)$ & $31(7.6)$ \\
\hline
\end{tabular}

OTC: Over the Counter

Table 4: Practice of community pharmacists on medication safety during pregnancy $(n=403)$.

\begin{tabular}{|c|c|}
\hline Variable & Frequency (\%) \\
\hline \multicolumn{2}{|c|}{$\begin{array}{l}\text { Do you advice pregnant women about non-prescription } \\
\text { drugs that not to be taken during pregnancy period }\end{array}$} \\
\hline Yes & $234(58.1)$ \\
\hline No & $169(41.9)$ \\
\hline \multirow{2}{*}{\multicolumn{2}{|c|}{$\begin{array}{l}\text { Do you advice pregnant women about prescription drugs } \\
\text { that not to be taken during pregnancy period and change it } \\
\text { by consultation of physician? }\end{array}$}} \\
\hline & \\
\hline Yes & $291(72.2)$ \\
\hline No & \\
\hline \multicolumn{2}{|c|}{$\begin{array}{l}\text { Do you advice pregnant women about herbal medicine } \\
\text { which should not to be taken during pregnancy }\end{array}$} \\
\hline Yes & $178(44.2)$ \\
\hline No & $225(55.8)$ \\
\hline \multicolumn{2}{|c|}{$\begin{array}{l}\text { Did you gone through any drug information resources for } \\
\text { any unknown drug before dispensing in pregnant women }\end{array}$} \\
\hline Yes & $198(49.1)$ \\
\hline No & $205(50.8)$ \\
\hline \multicolumn{2}{|c|}{$\begin{array}{l}\text { Do you regularly update your knowledge about safe } \\
\text { medication dispensing in pregnant women }\end{array}$} \\
\hline Yes & $153(37.9)$ \\
\hline No & $250(62.0)$ \\
\hline
\end{tabular}

of CPs are aware about OTC drugs $(45 ; 11.1 \%)$ and herbal medicine (36; $8.9 \%)$ use during pregnancy.

Community pharmacist's age more than 30 years (49.8\%, 34.3\%), working in urban settings $(57.7 \%, 41.4 \%)$, having B.Pharm or M. Pharm qualification $(54.9,70.0)$ and experience more than 15 years $(68.4 \%, 33.7 \%)$ was significantly associated with optimal knowledge and safe practice respectively with a $P<0.05$. This suggests that there is a need to upgrade
Table 5: Adequacy of knowledge, attitude and practice towards medication safety during pregnancy $(n=403)$.

\begin{tabular}{cc}
\hline Variable & Frequency (\%) \\
\hline Knowledge & \\
Optimal knowledge & $185(45.9)$ \\
Poor Knowledge & $218(54.1)$ \\
Attitude & \\
Positive attitude & $380(94.2)$ \\
Negative Attitude & $23(5.7)$ \\
Practice & $119(29.5)$ \\
Safe medication practice in pregnant women & $284(70.5)$ \\
Unsafe medication practice in pregnant women &
\end{tabular}

of minimum qualification to B.Pharm for practice of pharmacy in community setup. Upgrade of qualification for practice of pharmacy requires a lot of change in the Indian pharmaceutical law that takes a long period. Instantly, several measures need be taken to improve CPs knowledge about safe medication use during pregnancy like, free continuous educational programs about medication safety during pregnancy and providing readily available medication software to access the unbiased safety information about the drugs.

Irrespective of age, qualification, area of practice and experience, more than $90 \%$ of the CPs had shown a positive attitude towards medication safety during pregnancy. This may be due to CPs believed that medication safety is one of the major concern in the pregnancy period. Definitely, this positive attitude will gives a space for providing educational intervention to improve the knowledge and to channel this into a practice. The study will give insights for providing educational programs to CPs residing in Anantapur district. The study was conducted by self-administered questionnaire, so there is a risk of desirable bias in the study. The study was conducted in Anantapur district, so the results may not explored in nationwide. 
Table 6: Association of Socio-demographic characteristics with Optimal Knowledge, Positive Attitude and Safe Practice towards medication safety during pregnancy $(n=403)$.

\begin{tabular}{|c|c|c|c|c|c|c|c|c|c|c|}
\hline \multirow[t]{3}{*}{ Variable } & \multirow{2}{*}{$\frac{\text { Total }}{403}$} & \multicolumn{3}{|c|}{ Optimal Knowledge } & \multicolumn{3}{|c|}{ Positive Attitude } & \multicolumn{3}{|c|}{ Safe Practice } \\
\hline & & $\mathrm{N}$ & $\%$ & $\chi^{2}(P$-Value $)$ & $\mathrm{N}$ & $\%$ & $\chi^{2}(P$-Value $)$ & $N=$ & $\%$ & $\chi^{2}(P$-Value $)$ \\
\hline & & 185 & & & 380 & & & 119 & & \\
\hline Age: & & & & & & & $0.5(0.4408)$ & & & \\
\hline$\leq 30$ Years & 112 & 40 & 35.7 & $6.4(0.0108)$ & 104 & 92.8 & & 19 & 16.1 & $11.7(0.0006)$ \\
\hline$>30$ Years & 291 & 145 & 49.8 & & 276 & 94.8 & & 100 & 34.3 & \\
\hline Male & 345 & 164 & 47.5 & $2.5(0.109)$ & 330 & 95.6 & $8.231(0.004)$ & 100 & 28.9 & $0.339(0.560)$ \\
\hline Female & 58 & 21 & 36.2 & & 50 & 86.2 & & 19 & 32.7 & \\
\hline \multicolumn{11}{|l|}{ Location } \\
\hline Rural & 280 & 114 & 40.7 & $9.9(0.0016)$ & 264 & 94.2 & 0.0001 & 68 & 24.3 & $12.1(0.0004)$ \\
\hline Urban & 123 & 71 & 57.7 & & 116 & 94.3 & $(0.992)$ & 51 & 41.4 & \\
\hline D. Pharm & 232 & 91 & 39.2 & $9.8(0.0017)$ & 216 & 93.1 & $1.4(0.23)$ & 13 & 5.6 & $150.5(<0.00001)$ \\
\hline B. Pharm (or) & 171 & 94 & 54.9 & & 164 & 95.9 & & 106 & 70.0 & \\
\hline \multicolumn{11}{|l|}{ M. Pharm } \\
\hline \multicolumn{11}{|l|}{ Experience } \\
\hline$\leq 15$ Years & 172 & 27 & 15.7 & $110.2(<0.00001)$ & 160 & 93.0 & $0.89(0.343)$ & 41 & 23.8 & $4.6(0.0306)$ \\
\hline$>15$ Years & 231 & 158 & 68.4 & & 220 & 95.2 & & 78 & 33.7 & \\
\hline
\end{tabular}

\section{CONCLUSION}

The study found that community pharmacists are having a positive attitude and some knowledge about safe medication use in pregnant women. Still, there is a wide gap in knowledge levels and practices of CPs towards safe medication use in pregnant women. This gap can be fulfilled by providing focused educational intervention to CPs, based on the lacunas observed in the study.

\section{ACKNOWLEDGEMENT}

Authors like to thank all community pharmacists who are involved in the study and giving valuable information to promote safe use of medication during pregnancy.

\section{CONFLICT OF INTEREST}

The authors declare that there are no conflicts of interest.

\section{ABBREVIATIONS}

CP: Community Pharmacist; FDA: Food and Drug Administration;

KAP: Knowledge, Attitude and Practice; OCP: Oral Contraceptive Pill; OTC: Over the Counter; SD: Standard Deviation; USA: United States of America; WHO: World Health Organization.

\section{REFERENCES}

1. https://www.who.int/en/news-room/fact-sheets/detail/maternal-mortality.

2. Abasiubong F, Bassey EA, Udobang JA, Akinbami OS, Udoh SB, Idung AU. SelfMedication: Potential risks and hazards among pregnant women in Uyo, Nigeria. Pan Afr Med J. 2012;13:15. http://www.ncbi.nlm.nih.gov/pubmed/23308320

3. Mosley JF, Smith LL, Dezan MD. An overview of upcoming changes in pregnancy and lactation labeling information. Pharm Pract. 2015;13(2):605. http:// www.ncbi.nlm.nih.gov/pubmed/26131048

4. Ayad M, Costantine MM. Epidemiology of medications use in pregnancy. Semin Perinatol. 2015;39(7):508-11. http://www.ncbi.nlm.nih.gov/pubmed/26358804

5. Devkota R, Khan GM, Alam K, Sapkota B, Devkota D. Impacts of counseling on knowledge, attitude and practice of medication use during pregnancy. BMC Pregnancy Childbirth. 2017;17(1):131. http://bmcpregnancychildbirth.biomedcentral.com/articles/10.1186/s12884-017-1316-6

6. Wyszynski DF, Shields KE. Frequency and type of medications and vaccines used during pregnancy. Obstet Med. 2016;9(1):21-7. http://www.ncbi.nlm.nih gov/pubmed/27512486

7. Banu GKA. A questionnaire based survey on knowledge, attitude and practices of medical practitioners regarding the prescribing of medications during pregnancy. Int J Reprod Contraception, Obstet Gynecol. 2016;5(4):984-8. http:// www.ijrcog.org/index.php/ijrcog/article/view/851

8. Zaki NM, Albarraq AA. Use, attitudes and knowledge of medications among pregnant women: A Saudi study. Saudi Pharm J SPJ Off Publ Saudi Pharm Soc. 2014;22(5):419-28. http://www.ncbi.nlm.nih.gov/pubmed/25473330

9. Samuel N, Einarson A. Medication management during pregnancy: Role of the pharmacist. Int J Clin Pharm. 2011;33(6):882-5. http://www.ncbi.nlm.nih.gov/ pubmed/21915759

10. Alrabiah Z, Al-Arifi MN, Alghadeer SM, Wajid S, AlQahtani A, Almotari N, et al. Knowledge of community pharmacists about the risks of medication use during pregnancy in central region of Saudi Arabia. Saudi Pharm J SPJ Off Publ Saudi Pharm Soc. 2017;25(7):1093-6. http://www.ncbi.nlm.nih.gov/pubmed/29158721

11. Jagarlamudi A, Begum A, Teegala M. A Survey Based Study for the Assessment of Knowledge and Practice of Community Pharmacy Personnel on Good Pharmacy Practice in Hyderabad, India. Indian J Pharm Pract. 2018;11(1):14-24 http://ijopp.org/article/591

12. George J. Optimising medication use during pregnancy: The potential role of pharmacists. Int J Pharm Pract. 2011;19(2):81-3. http://www.ncbi.nlm.nih.gov/ pubmed/21385238

13. Kamuhabwa A, Jalal R. Drug use in pregnancy: Knowledge of drug dispensers and pregnant women in Dares Salaam, Tanzania. Indian J Pharmacol. 2011;43(3):345. http://www.ijp-online.com/text.asp?2011/43/3/345/81503

14. Morgan MA, Cragan JD, Goldenberg RL, Rasmussen SA, Schulkin J. Obstetrician-gynaecologist knowledge of and access to information about the risks of medication use during pregnancy. J Matern Neonatal Med. 2010;23(10):1143 50. http://www.tandfonline.com/doi/full/10.3109/14767051003653252

15. Damase-Michel C, Pichereau J, Pathak A, Lacroix I, Montastruc JL. Perception of teratogenic and foetotoxic risk by health professionals: A survey in Midi-Pyrenees area. Pharm Pract. 2008;6(1):15-9. http://www.ncbi.nlm.nih.gov/ pubmed/25170360

16. Duraz AY, Khan SA. Knowledge, Attitudes and Awareness of Community Pharmacists Towards the Use of Herbal Medicines in Muscat Region. Oman Med J. 2011;26(6):4513. http://www.omjournal.org/fultext_PDF.aspx?DetailsID=177\&p $\mathrm{df}=$ images/177_M_Deatials_Pdf_.pdf\&type $=$ pdf 